\title{
New Flagship Universities: apontando caminhos para universidades mais relevantes ${ }^{1}$
}

\section{New Flagship Universities: directions for more relevant universities}

\begin{abstract}
Douglass, John Aubrey (Ed.). (2016). The New Flagship University: changing the paradigm from global ranking to national relevancy. New York: Palgrave Macmillan.
\end{abstract}

Flávia Soares de Oliveira Colus (i)

(i) Universidade Estadual de Campinas - UNICAMP, Campinas, SP, Brasil. https://orcid.org/00000002-0485-7891, flaviacolus@hotmail.com.

As universidades estão há muitos séculos presentes em nossa sociedade. Seu papel e missão, entretanto, são constantemente adaptados, tendo se modificado à medida que a própria sociedade se modificou. Atualmente, é possível notar um movimento em que

governos e ministérios estão, cada vez mais, esperando e demandando que suas universidades nacionais realizem funções que transcendem seu senso de propósito tradicional, incluindo um papel em inovação e desenvolvimento econômico, na promoção da igualdade social e no fomento da sustentabilidade ambiental (Bernasconi \& Calderón, 2016, p. 139, tradução nossa).

Estes papéis nem sempre se veem representados nos rankings que se propõem a estabelecer as melhores universidades do mundo. Para garantir a comparação de milhares de universidades, os rankings internacionais utilizam critérios simplificados de avaliação, que perdem em profundidade de análise e acabam por não considerar particularidades e

${ }^{1}$ Normalização, preparação e revisão textual: Douglas Mattos (Tikinet) - revisao@tikinet.com.br 


\section{pro.posıções}

http://dx.doi.org/10.1590/1980-6248-2019-0006

\section{$e$-ISSN 1980-6248}

regionalidades. Além disso, alguns critérios utilizados, como a quantidade de publicações, podem ter efeitos nefastos na qualidade das universidades, com foco na quantidade e não na qualidade ou no impacto das produções científicas da instituição (Butler \& Mulgan, 2013).

Neste contexto, o professor John Aubrey Douglass, da Universidade da Califórnia (em Berkeley), em seu livro The New Flagship University: changing the paradigm from global ranking to national relevancy, desenvolve o conceito de New Flagship University como um modelo completo de uma universidade moderna, referência regional e internacionalmente. O modelo é, em parte, resposta à crescente valorização dos rankings e da posição de World Class University (WCU), sendo "uma reação a esta visão míope e poderosa do que universidades líderes devem fazer e alcançar" (Douglass, 2016, p. 14, tradução nossa).

$\mathrm{Na}$ introdução e no primeiro capítulo do livro, o autor vem justamente problematizar a busca cega por melhores posições nos rankings internacionais. Entre as principais críticas desenvolvidas está a de que os rankings se apresentam como um jogo de soma zero, em que apenas algumas universidades atingem as melhores posições, enquanto as outras ficam às margens do modelo. Outra crítica colocada por Douglass é que os rankings "frequentemente falham em avaliar as atividades e resultados mais amplos das universidades e perdem vista das necessidades econômicas e de mobilidade socioeconômica de seus países" (Douglass, 2016, p. 3, tradução nossa). O livro tensiona os propósitos de relevância internacional com a relevância regional e local no momento em que a maioria dos esforços das universidades estão voltados para relevância internacional e posições em rankings mundiais.

Em contraste com o conceito de WCU e com os rankings internacionais, o modelo proposto por Douglass tem a intenção de apontar caminhos, em vez de ser um checklist ou uma competição. O termo flagship, se retomarmos a origem náutica da palavra, seria o navio líder, aquele que aponta os rumos. O modelo da New Flagship University serve como insumo para o autoaperfeiçoamento das universidades e dos sistemas nacionais de Ensino Superior, e não como avaliador externo.

Apesar das críticas, fica claro que a intenção de Douglass não é substituir os rankings, que seu modelo não é incompatível com a noção de WCU, e muito menos com a busca por relevância internacional. A proposta, como será explicado mais à frente, é apenas que o desempenho internacional não seja a principal missão das universidades. Voltando à analogia 


\section{pro.posıções}

http://dx.doi.org/10.1590/1980-6248-2019-0006

náutica, podemos dizer que o modelo busca a internacionalização sem se esquecer de onde a universidade está ancorada.

Ao colocar o nome de "New Flagship University" em seu modelo, fica implícito que havia uma "antiga" flagship university. Durante o segundo e terceiro capítulo, o autor passa justamente a descrever e caracterizar os modelos da Traditional Flagship University e da New Flagship University. Enquanto ambas seriam universidades líderes na nação, a flagship tradicional acabaria por ser mais um caminho para as elites chegarem ao poder do que uma instituição que promove mudanças sociais. A New Flagship University traz o diferencial de valorizar "um acesso amplo, uma vasta gama de programas acadêmicos, engajamento com a economia local e liderança no desenvolvimento da educação pública" (Douglass, 2016, p. 33, tradução nossa). O modelo reflete sobre as relações da universidade com a sociedade e propõe uma combinação de impacto econômico e social, em que a universidade esteja atenta e preocupada com as questões de sua comunidade e região, mas é preservada a liberdade e autonomia acadêmica, de maneira que a universidade não se torne puramente utilitária.

O terceiro capítulo é, então, dedicado a destrinchar o modelo da New Flagship University, explicando cada um de seus eixos. O modelo trabalha com quatro esferas de análise para as universidades: (i) a universidade no sistema nacional de Educação Superior; (ii) missões de ensino e pesquisa; (iii) serviço público e engajamento econômico; e (iv) gestão e prestação de contas. Estas categorias se organizam conforme descrito na Figura 1. 


\section{pro.posições \\ $e$-ISSN 1980-6248}

Figura 1 - Os quatro eixos da New flagship university

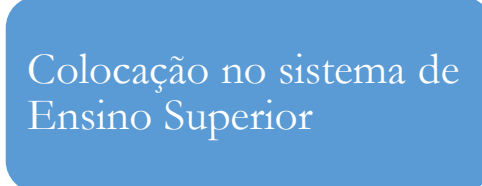

Serviço público e

engajamento econômico

com o desenvolvimento

regional

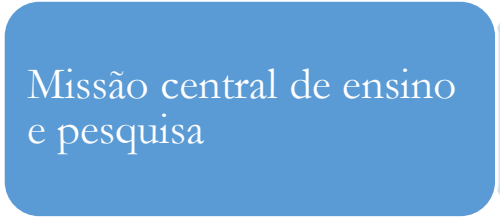

Governança e prestação

de contas
- Posição no sistema de Ensino Superior

- Área de serviço definida

- Admissões seletivas

- Engajamento e serviço

- Engajamento economico regional/Transferência de tecnologia

- Educação continuada

- Relação com as escolas

- Graduação

- Pós-graduação

- Pesquisa

- Engajamento internacional

- Autonomia institucional

- Governança

- Liberdade acadêmica

- Garantias de qualidade

- Liderança

Fonte: adaptado de Douglass (2016).

Algumas das características da New Flagship University merecem ser ressaltadas. Douglass enfatiza a importância da colocação da universidade no sistema de Ensino Superior, com uma boa definição de seu papel no sistema nacional de ensino. Aqui ele ressalta também a importância da diferenciação dentro dos sistemas, já que, para o autor, não seria possível que um país tenha todas as suas universidades com foco intensivo em pesquisa. A definição do papel da universidade no sistema nacional de ensino passaria também pela definição de seu papel no desenvolvimento econômico do país.

Além disso, há uma preocupação com o perfil dos estudantes que ingressam nestas universidades, para que elas não sejam ferramentas de manutenção e concentração de poder. $O$ ideal da New Flagship University propõe que as universidades considerem em seus processos seletivos "o contexto socioeconômico de seus estudantes, representatividade geográfica e abram exceções para estudantes com talentos especiais" (Douglass, 2016 p. 44, tradução nossa). Ela deve buscar os melhores estudantes, mas seus processos seletivos devem ser diversificados para que ela de fato atraia esses estudantes, e não apenas aqueles com maiores condições financeiras. 


\section{pro.posições}

http://dx.doi.org/10.1590/1980-6248-2019-0006

\section{$e$-ISSN 1980-6248}

$\mathrm{Na}$ esfera de "serviço público e engajamento econômico com o desenvolvimento regional", cabe destacar os aspectos da educação universitária que preparam os estudantes para o mercado de trabalho (com foco em apoiar as necessidades das indústrias locais) e a transferência de tecnologia. As proposições de Douglass sobre a transferência de tecnologia buscam encontrar um ponto de equilíbrio em que a universidade consiga se mostrar aberta a parcerias com empresas sem perder a independência acadêmica. Ele propõe que esta relação deve estimular o uso das tecnologias e ideias geradas na universidade pelo mercado, mas que deve ser mantida a liberdade de publicação pela instituição. A defesa de que a pesquisa científica deve poder ser publicada livremente dialoga com estudiosos da ciência e tecnologia como Merton (1979), que coloca o comunismo como parte do ethos da ciência, a partir do qual as descobertas científicas estariam "destinadas à comunidade" (p. 45). Como a New Flagship University seria uma universidade intensiva em pesquisa, Douglass traz a preocupação de se preservarem os princípios da ciência, e sua discussão sobre evitar que empresas restrinjam a divulgação dos resultados científicos das universidades lembra a discussão de Merton sobre o comunismo, a propriedade intelectual e o imperativo da comunicação dos resultados.

O último eixo do modelo que deve ser destacado aqui é o da "governança e prestação de contas". O modelo de governança de Douglass propõe uma universidade autônoma, com pouca dependência governamental, que tenha liderança eficaz e um controle de qualidade interno rigoroso. A liderança deve ter caráter executivo, e a instituição desenvolver uma cultura de melhoramentos internos.

As últimas duas esferas destacadas, de "serviço público e engajamento econômico com o desenvolvimento regional" e de "governança e prestação de contas", apresentam grandes similaridades com as ideias da Universidade Empreendedora de Burton Clark (2013). A ênfase na responsividade às necessidades da sociedade com poder de adaptabilidade está presente em ambas as propostas. A ideia de uma governança mais eficiente e menos dependente de fundos únicos do governo também vai ao encontro das proposições de Clark (2013).

O modelo de Douglass com certeza é complexo, e ao longo do livro é fácil perder de vista uma premissa ressaltada nos primeiros capítulos, de que não devemos transformar a New Flagship University em um checklist da universidade perfeita. Como o autor passa detalhadamente pelos diversos aspectos deste tipo de universidade, uma leitura apressada pode levar a entender o modelo como uma sequência de critérios a serem seguidos pelas instituições. 


\section{pro.posıções}

http://dx.doi.org/10.1590/1980-6248-2019-0006

\section{$e$-ISSN 1980-6248}

É preciso que o leitor se desvie desta armadilha e entenda o modelo como um tipo ideal, que não encontra equivalentes no mundo real.

Os capítulos descritos até o momento compõem a primeira parte do livro, escrita por Douglass e que serve como apoio teórico e conceitual para as análises que se seguem na segunda parte do livro. Esta segunda parte é composta por mais quatro capítulos e um epílogo, cada um deles escrito por diferentes autores. Esses capítulos buscam analisar as universidades e sistemas de Ensino Superior em diferentes partes do mundo à luz do modelo da New Flagship University. O livro apresenta a análise de John N. Hawkins sobre as universidades asiáticas, de Andrés Bernasconi e Daniela Véliz Calderón sobre a América Latina, de Bjørn Stensaker e Tatiana Fumasoli sobre as universidades escandinavas, e de Isak Froumin e Oleg Leshukov sobre as universidades soviéticas.

No capítulo sobre a América Latina, são feitas análises interessantes sobre como o modelo de Douglass encontra dificuldades para se traduzir em países em desenvolvimento. Uma universidade abrangente com pesquisa de qualidade como a New Flagship University com certeza é custosa, e parte dos desafios enfrentados na América Latina diz respeito à alocação de recursos. A falta de diferenciação das instituições dentro de nossos sistemas de Ensino Superior faz com que os recursos sejam espalhados muito largamente, o que dificulta a criação de universidades abrangentes de excelência (Bernasconi \& Calderón, 2016). Além disso, a gestão das universidades latino-americanas se mostra longe do idealizado por Douglass ou Burton Clark, com processos ineficientes e gestão quase parlamentar, muito longe de atender as demandas e a dinamicidade das sociedades em que se inserem.

O livro organizado por John Aubrey Douglass se mostra como muito mais do que um arcabouço conceitual para um novo modelo de análise das universidades modernas. Ele apresenta uma discussão introdutória muito relevante sobre as dificuldades enfrentadas pelas universidades contemporâneas ao orientar suas práticas internas e buscar qualidade. Ao estruturar a New Flagship University, o autor passa por todas as principais discussões de Ensino Superior, indo desde currículo até financiamento e relação com indústrias. Por fim, as discussões sobre o modelo em relação às universidades no mundo trazem à tona as dificuldades da prática, evidenciando as necessidades de adaptação para cada região e contribuindo para um debate mais informado sobre a realidade das instituições acadêmicas. Dessa maneira, o livro serve também 


\section{pro.posıções}

http://dx.doi.org/10.1590/1980-6248-2019-0006

$e$-ISSN 1980-6248

como uma introdução ao debate sobre as universidades modernas, suas funções, papéis e as expectativas que devem cumprir.

\section{Referências}

Bernasconi, A., \& Calderón, D. V. (2016). Latin American Flagship Universities: From Early Notions of State Building to Seeking a Larger Role in Society. In J. A. Douglass (Ed.), The New Flagship University: changing the paradigm from global ranking to national relevancy (pp. 139-152). New York: Palgrave Macmillan.

Butler, P., \& Mulgan, R. (2013). Can academic freedom survive performance-based research funding? Victoria University of Wellington Law Review, 44, 487-520.

Clark, B. R. (2013). Sustaining change in universities: continuities in case studies and concepts. Tertiary Education and Management, 9, 99-116. doi:10.1023/A:1023538118918

Douglass, J. A. (Ed.). (2016). The New Flagship University: changing the paradigm from global ranking to national relevancy. New York: Palgrave Macmillan.

Merton, R. K. (1979). Os imperativos institucionais da ciência. In J. D. Deus (Org.), A crítica da ciência (pp. 37-52). Rio de Janeiro: Zahar.

Submetido à avaliação em 08 de janeiro de 2019; aceito para publicaşão em 28 de abril de 2019. 